\title{
A experiência na formação interdisciplinar dos residentes em obstetrícia do hospital Sofia Feldman
}

\author{
Ana Paula da Silva Amaral, Fernanda Mitre Cotta, Danúbia Mariane Barbosa Jardim
}

\begin{abstract}
Resumo
O Hospital Sofia Feldman (HSF) pertencente à Fundação de Assistência Integral à Saúde (FAIS) é uma instituição filantrópica de direito privado localizada no município de Belo Horizonte (BH), que atende uma população de aproximadamente 500.000 pessoas dos distritos sanitários norte e nordeste, atendendo exclusivamente usuários do SUS. Os princípios institucionais do HSF envolvem o desenvolvimento de ações de atenção integral à saúde da comunidade, em especial da mulher e da criança, no modelo multi e interdisciplinar. Na assistência a mulher durante o trabalho de parto e parto são preconizadas práticas clínicas baseadas em evidências científicas como: estimular e favorecer a presença do acompanhante em tempo integral, incentivar o parto normal, oferecer métodos farmacológicos e não farmacológicos de alívio da dor durante o trabalho de parto. Por se tratar de em Hospital de Ensino, são oferecidos Programas de Residência que visam formar profissionais de saúde no âmbito materno-infantil embasados nos princípios e diretrizes do Sistema Único de Saúde (SUS). Hoje contamos com os Programas de residência Multiprofissional em Neonatologia, Enfermagem Obstétrica, Médica em Ginecologia/Obstetrícia e Médica em Neonatologia, com a oferta anual de 60 vagas, com todos os cursos cadastrados no Ministério da educação e Cultura e organizados pautados nas resoluções e portarias ministeriais. Relatar a experiência de residentes dos Programas de residência em Enfermagem Obstétrica e residência médica em Ginecologia e Obstetrícia na assistência à mulher no HSF, Belo Horizonte, Minas Gerais, Brasil. Trata-se de um relato de experiência sobre os Programas de Residência, no qual se descreve a prática e a vivência de residentes de enfermagem e medicina durante a assistência ao ciclo gravídico-puerperal. Nos Programas de Residência do Hospital Sofia Feldman, desde o início do processo de formação, os residentes são estimulados a trabalharem em uma perspectiva interdisciplinar, articulando e integrando os saberes, discutindo as situações clínicas das mulheres e recém-nascidos assistidos na instituição, para a tomada de condutas clínicas e diretrizes assistenciais pautadas nos princípios da humanização. Além disso, mensalmente, são realizados grupos de discussão de casos reais que são abertos para todas as categorias profissionais, constituindo um espaço de reflexão da prática diária, oportunidade de discutir condutas, ampliar o conhecimento e (re) significar as suas práticas cotidianas. Os espaços conjuntos de formação colaboram para a integração e efetivação desta abordagem interdisciplinar necessária para uma assistência integral, qualificada, singular, humana, digna e respeitosa. A forma como é operacionalizada a assistência no HSF, para além de uma equipe multiprofissional, mas em uma perspectiva interdisciplinar desde o início da formação dos residentes, contribui significativamente para o exercício do trabalho em equipe e na construção de uma assistência mais efetiva e humana as gestantes, parturientes e puérperas. Para as residentes, a discussão das situações clínicas e condutas entre as categorias profissionais permite a melhor condução da assistência e da dinâmica de trabalho, além de favorecer uma assistência singular a cada mulher, recém-nascido e família assistida.
\end{abstract}

Descritores: Obstetrícia; Internato e Residência; Equipe de Assistência ao Paciente. 